\title{
Article \\ Bee Bread Ameliorates Vascular Inflammation and Impaired Vasorelaxation in Obesity-Induced Vascular Damage Rat Model: The Role of eNOS/NO/cGMP-Signaling Pathway
}

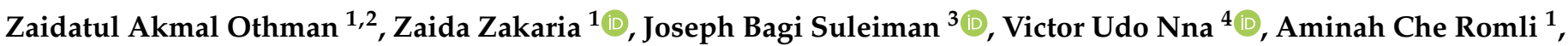 \\ Wan Syaheedah Wan Ghazali ${ }^{1}$ and Mahaneem Mohamed ${ }^{1,5, *(\mathbb{D}}$ \\ 1 Department of Physiology, School of Medical Sciences, Universiti Sains Malaysia, Kubang Kerian 16150, \\ Kelantan, Malaysia; zaidaakmal@unisza.edu.my (Z.A.O.); zaida_zakaria@ymail.com (Z.Z.); \\ aminahr@usm.my (A.C.R.); syaheeda@usm.my (W.S.W.G.) \\ 2 Unit of Physiology, Universiti Sultan Zainal Abidin, Kuala Terengganu 20400, Terengganu, Malaysia \\ 3 Department of Science Laboratory Technology, Akanu Ibiam Federal Polytechnic, P.M.B 1007, Unwana, \\ Ebonyi State, Nigeria; bagisuleiman@yahoo.com \\ 4 Department of Physiology, Faculty of Basic Medical Sciences, College of Medical Sciences, University of \\ Calabar, Calabar, P.M.B. 1115, Calabar, Cross River State, Nigeria; victor2nna@gmail.com \\ 5 Unit of Integrative Medicine, School of Medical Sciences, Universiti Sains Malaysia, Kubang Kerian 16150, \\ Kelantan, Malaysia \\ * Correspondence: mahaneem@usm.my; Tel.: +60-9767-6158
}

Citation: Othman, Z.A.; Zakaria, Z.; Suleiman, J.B.; Nna, V.U.; Che Romli, A.; Wan Ghazali, W.S.; Mohamed, M. Bee Bread Ameliorates Vascular Inflammation and Impaired

Vasorelaxation in Obesity-Induced Vascular Damage Rat Model: The Role of eNOS/NO/cGMP-Signaling Pathway. Int. J. Mol. Sci. 2021, 22, 4225. https://doi.org/10.3390/ ijms22084225

Academic Editor: Hidenori Koyama

Received: 14 April 2021

Accepted: 17 April 2021

Published: 19 April 2021

Publisher's Note: MDPI stays neutral with regard to jurisdictional claims in published maps and institutional affiliations.

Copyright: (c) 2021 by the authors. Licensee MDPI, Basel, Switzerland. This article is an open access article distributed under the terms and conditions of the Creative Commons Attribution (CC BY) license (https:/ / creativecommons.org/licenses/by/ $4.0 /)$.
Abstract: Obesity and hyperlipidemia are major risk factors for developing vascular diseases. Bee bread (BB) has been reported to exhibit some biological actions, including anti-obesity and antihyperlipidemic. This study aims to investigate whether bee bread can ameliorate vascular inflammation and impaired vasorelaxation activity through eNOS/NO/cGMP pathway in obese rats. Forty male Sprague-Dawley rats were randomly divided into four groups ( $n=10 /$ group), namely: control (normal group), obese rats (OB group), obese rats treated with bee bread $(0.5 \mathrm{~g} / \mathrm{kg} / \mathrm{day}, \mathrm{OB} / \mathrm{BB}$ group) and obese rats treated with orlistat ( $10 \mathrm{mg} / \mathrm{kg} /$ day, OB/OR group). The latter three groups were given a high-fat diet (HFD) for 6 weeks to induced obesity before being administered with their respective treatments for another 6 weeks. After 12 weeks of the total experimental period, rats in the OB group demonstrated significantly higher Lee obesity index, lipid profile (total cholesterol, triglyceride, low-density lipoprotein), aortic proinflammatory markers (tumor necrosis factor- $\alpha$, nuclear factor- $\kappa \beta)$, aortic structural damage and impairment in vasorelaxation response to acetylcholine (ACh). Bee bread significantly ameliorated the obesity-induced vascular damage manifested by improvements in the lipid profile, aortic inflammatory markers, and the impaired vasorelaxation activity by significantly enhancing nitric oxide release, promoting endothelial nitric oxide synthase (eNOS) and cyclic guanosine monophosphate (cGMP) immunoexpression. These findings suggest that the administration of bee bread ameliorates the impaired vasorelaxation response to ACh by improving eNOS/NO/cGMP-signaling pathway in obese rats, suggesting its vascular therapeutic role.

Keywords: bee bread; obesity; hyperlipidemia; vasorelaxation; eNOS/NO/cGMP pathway

\section{Introduction}

Obesity has contributed to a major burden of disease in developing countries worldwide [1]. Obese individuals are predisposed to vascular diseases, particularly coronary and cerebellar artery diseases, affecting their mobility and mortality as the diseases progress [2]. A dramatic rise in the number of cardiovascular deaths has been projected in the year 2030 [3], and obesity accounted for 54.8\% among the risk factors associated with cardiovascular disease (CVD) following hypercholesterolemia (51.5\%), hypertension (39.3\%), smoking (16.3\%), diabetes mellitus (7.8\%) and alcohol consumption (1.4\%) [4]. 
Higher circulating free fatty acids contributed by excessive fatty diet trigger the adipose tissue and systemic inflammation, which indicates a crucial interplay between obesity and hyperlipidemia [5]. In the presence of high circulatory lipids, tumor necrosis factor (TNF)- $\alpha$ can activate nuclear factor (NF)- $k \beta$. The acute increase in the level of NF- $k \beta$, therefore, increases the expression of NF- $\mathrm{\beta} \beta$-derived proinflammatory markers. These include adhesion molecules and chemokine inflammatory mediators that are capable of triggering monocyte binding and infiltration into the sub-endothelial region, as well as inducing smooth muscle migration and proliferation, hence, accelerating developing atherosclerosis by causing vascular structural and functional damages [6]. The increase in TNF- $\alpha / \mathrm{NF}-\kappa \beta$ activation was also seen in the aorta of rats fed with a high-fat diet (HFD) and $10 \%$ fructose-induced dyslipidemia for 12 weeks [7].

Studies have shown that obesity-related vascular damage is also linked to a low level of nitric oxide (NO) formation, which is primarily generated by the endothelial layer, the absence of which is described as endothelial dysfunction [8]. In normal and healthy individuals, NO is primarily generated by endothelium nitric oxide synthase (eNOS) in the vascular endothelial layer and plays a crucial role in the regulation of vascular tone and blood flow, allowing for vasorelaxation [9]. NO production might be lost by the destruction of cofactors that are involved in their generation and is regulated by the presence of plateletderived factors, shear stress, acetylcholine (ACh) and cytokines [10].

There are several pathways, which affect vasorelaxation. However, the most promising therapeutic path that modulates NO is via targeting eNOS/NO/cGMP pathway. NO can stimulate the production of cyclic $3^{\prime}-5^{\prime}$ guanosine monophosphate (cGMP) signaling through the activation of soluble guanylate cyclase (sGC) to induce smooth muscle relaxation through actin-myosin light chain [11]. The imbalance of functionality and availability of eNOS, which acts through sGC and cGMP, also further reduces functional NO and subsequently impairs the vasorelaxation response [12]. Previous studies that used obese mice [13] and rat [14] models with reduced NO and cGMP levels demonstrated vasorelaxation failure. Therefore, the eNOS/NO/cGMP-signaling pathway plays a critical role in vascular dysfunction in obesity-related vascular damage.

Nowadays, many bee products have been recognized as supplements for humans, as they are rich in nutrients and antioxidants. Propolis, pollen and royal jelly have been reported to produce endothelium-dependent vasorelaxation of arteries in L-NAME-induced hypertensive rats $[15,16]$. Bee bread is one of the major bee products apart from honey, propolis and royal jelly, and it is commonly used to maintain general health by traditional users in Malaysia. It is made from a mixture of honey, bee pollen, and bee saliva [17]. The bees collect and store them in a beehive, and the bee bread takes about two weeks to be fermented, which gives higher nutritive value and acidity compared to other bee's products [18]. Bee bread has been shown to possess biological functions such as antimicrobial [19], antitumor [20], and hepatoprotective [21] properties. It has been shown to possess high antioxidant activity due to the presence of active phenolic compounds, such as caffeic acids, ferulic acids, kaempferol, apigenin, and isorhamnetin [22]. Bee bread has a favorable effect on lipid profiling as it demonstrates a reduction in LDL level, and its role as an anti-obesity product was clearly demonstrated in our previous study where bee bread reduced Lee obesity index and the progression of atherosclerosis [22]. However, to date, no study has been reported on the therapeutic role of bee bread, particularly its effect on vascular inflammation in obese rats, and the mechanism involved for its vasorelaxant activity is far from clear. Therefore, this study was designed to determine the ameliorative effect of bee bread on vascular inflammation and impaired vasorelaxation activity in obese male rats, emphasizing eNOS/NO/cGMP-signaling pathway to meet the criteria for the probable vascular therapeutic role. 


\section{Results}

\subsection{Effect of Bee Bread on Lee Obesity Index, Lipid Profile and Atherogenic Ratios in Obese Rats}

As shown in Table 1, the OB group had a significant increase in Lee obesity index compared to the normal group. Treatment with bee bread and orlistat significantly reduced the Lee obesity index in the $\mathrm{OB} / \mathrm{BB}$ and $\mathrm{OB} / \mathrm{OR}$ groups compared to the $\mathrm{OB}$ group. Biochemical analysis of lipid profile was performed to find the changes in lipid levels. The OB group had significantly higher levels of TC, TG and LDL compared to the normal group. Treatment with bee bread significantly reduced these levels, which was comparable to the orlistat group, except for HDL level, which was found to be significantly increased in $\mathrm{OB} / \mathrm{OR}$ group in respect to the OB group. OB group had significant increases in AI, CRI-1, and CRI-11 by $79.58 \%, 50.13 \%$ and $72.96 \%$, respectively, compared to the normal group. Treatment with bee bread significantly reduced AI, CRI-1 and CRI-11 by $25 \%, 27.71 \%$, and $28.20 \%$, respectively, compared to the OB group. Meanwhile, treatment with orlistat significantly reduced AI, CRI-1 and CRI-11 by $41.27 \%, 38.01 \%$, and $33.13 \%$, respectively, compared to the OB group.

Table 1. Effect of bee bread on Lee obesity index, lipid profile and atherogenic ratios.

\begin{tabular}{ccccc}
\hline Parameters & Normal & OB & OB/BB & OB/OR \\
\hline Lee obesity index & $304.85(7.20)$ & $332.13(7.15)^{\mathrm{a}}$ & $311.42(6.94)^{\mathrm{b}}$ & $316.70(7.81)^{\mathrm{b}}$ \\
TC (mmol/L) & $1.61(0.16)$ & $2.63(0.65)^{\mathrm{a}}$ & $1.99(0.15)^{\mathrm{b}}$ & $2.05(0.20)^{\mathrm{b}}$ \\
TG (mmol/L) & $0.50(0.08)$ & $0.92(0.10)^{\mathrm{a}}$ & $0.59(0.16)^{\mathrm{b}}$ & $0.66(0.14)^{\mathrm{b}}$ \\
LDL (mmol/L) & $0.93(0.19)$ & $1.65(0.57)^{\mathrm{a}}$ & $1.10(0.35)^{\mathrm{b}}$ & $1.08(0.24)^{\mathrm{b}}$ \\
HDL (mmol/L) & $0.41(0.10)$ & $0.40(0.05)^{\mathrm{a}}$ & $0.49(0.10)$ & $0.66(0.09)^{\mathrm{a}, \mathrm{b}, \mathrm{c}}$ \\
Atherogenic index & $2.361(0.57)$ & $4.24(0.73)^{\mathrm{a}}$ & $3.18(0.52)^{\mathrm{b}}$ & $2.49(0.62)^{\mathrm{b}}$ \\
Castelli risk index 1 & $3.75(0.96)$ & $5.63(0.33)^{\mathrm{a}}$ & $4.07(0.47)^{\mathrm{b}}$ & $3.49(0.62)^{\mathrm{b}}$ \\
Castelli risk index 11 & $2.04(0.56)$ & $3.53(0.69)^{\mathrm{a}}$ & $2.53(0.33)^{\mathrm{b}}$ & $2.36(0.51)^{\mathrm{b}}$ \\
\hline
\end{tabular}

Data are presented as mean (standard deviation), $n=10 /$ group. $^{\text {a }} p<0.05$ compared to normal group, ${ }^{\mathrm{b}} p<0.05$ compared to the OB group, ${ }^{\mathrm{c}} p<0.05$ compared to the OB/BB group. All data were analyzed using one-way ANOVA followed by Tukey's post hoc test. OB: obese, OB/BB: obese and bee bread $0.5 \mathrm{~g} / \mathrm{kg} /$ day, OB/OR: obese and orlistat $10 \mathrm{mg} / \mathrm{kg} /$ day, TC: total cholesterol, TG: triglyceride, LDL: low-density lipoprotein, HDL: high-density lipoprotein.

\subsection{Effect of Bee Bread on Aortic Inflammatory Markers in Obese Rats}

Vascular inflammation is an important step in developing vascular damage, which progresses to atherosclerosis. We determined the levels of aortic proinflammatory markers, namely: TNF- $\alpha$ and NF- $\kappa \beta$, as well as the level of the aortic anti-inflammatory marker, IL-10. As indicated in Figure 1, rats in the OB group had a significant increase in the levels of aortic TNF- $\alpha$ and NF- $\kappa \beta$ compared to the normal group. Treatment with bee bread and orlistat had significantly abolished the increases of these vascular inflammatory markers compared to the OB group (Figure 1A,B). On the other hand, the level of IL-10 was found to be significantly decreased in the OB group compared to the normal group. Bee bread and orlistat alleviated the vascular inflammation by significantly increasing the aortic IL-10 level compared to the OB group (Figure 1C). 


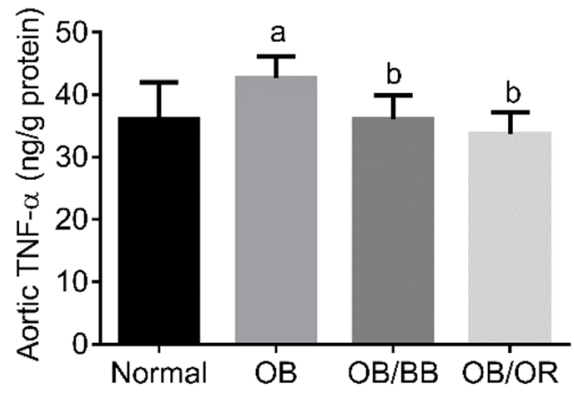

(A)

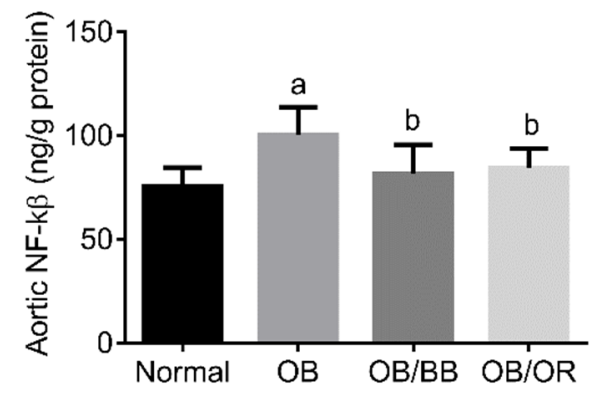

(B)

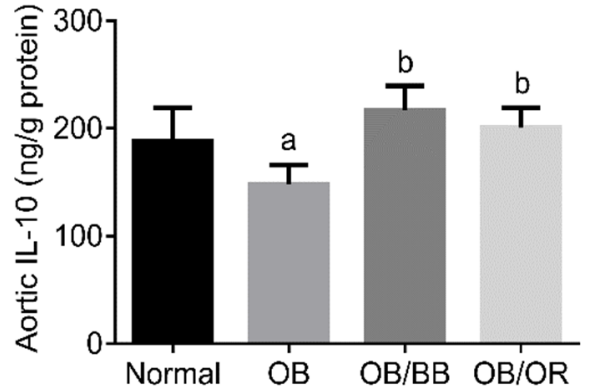

(C)

Figure 1. Protein levels of pro- and anti-inflammatory markers (A) TNF- $\alpha,(\mathbf{B}) \mathrm{NF}-\mathrm{k} \beta$ and (C) IL-10 in the aorta of all experimental groups. All results are expressed as mean and standard deviation, $n=10 /$ group. ${ }^{\text {a }} p<0.05$ compared to normal group, ${ }^{b} p<0.05$ compared to the OB group. All data were analyzed using one-way ANOVA followed by Tukey's post hoc test. OB: obese, OB/BB: obese and bee bread $0.5 \mathrm{~g} / \mathrm{kg} /$ day, OB/OR: obese and orlistat $10 \mathrm{mg} / \mathrm{kg} / \mathrm{day}$, IL-10: interleukin-10, TNF- $\alpha$, tumor necrosis factor-alpha, NF-k $\beta$ : nuclear factor-kappa $\beta$.

\subsection{Effect of Bee Bread on Endothelium-Dependent Vascular Reactivity in Obese Rats}

Vascular reactivity was performed to determine vascular endothelial responses towards ACh. In normal conditions, ACh acts as an endothelium-dependent vasodilator by inducing relaxation in response to PE-induced vasoconstriction. As shown in Table 2, the endothelium-dependent vasorelaxation induced by $A C h$ in the OB group $\left(E_{\max } 65.71 \%\right.$, $\mathrm{pE}_{50} 6.28$ ) was significantly impaired compared to the normal group ( $\mathrm{E}_{\max } 98.43 \%, \mathrm{pE}_{50}$ 6.77). Bee bread treatment ameliorated these impairments by increasing the endotheliumdependent vasorelaxation response in a dose-dependent manner, with $\mathrm{E}_{\max }$ of $87.50 \%$ yielding a $\mathrm{pE}_{50}$ value of 6.77. A similar finding also demonstrated by the OB/OR group, which had a significantly higher $\mathrm{E}_{\max } 82.91 \%$ value compared to the OB group and significantly lower value compared to the normal group, without a significant change in $\mathrm{pE}_{50}$ value. Bee bread and orlistat had no significant effects on the contraction induced by $\mathrm{KCl}$ and PE. Figure 2 demonstrated the percentage of relaxation response (Figure 2A) and schematic graphs (Figure 2B-E) of endothelium-intact thoracic aortic rings precontracted with increasing concentration of PE from all groups. As the concentration of PE increased, the relaxation responses of the thoracic aorta of the OB group were markedly lowered compared to the normal group. Meanwhile, the relaxation responses were markedly increased in the thoracic aorta of $\mathrm{OB} / \mathrm{BB}$ and $\mathrm{OB} / \mathrm{OR}$ groups compared to the $\mathrm{OB}$ group.

Table 2. Ex vivo aortic isolated tissue bath assay.

\begin{tabular}{ccccc}
\hline Parameters & Normal & OB & OB/BB & OB/OR \\
\hline $\mathrm{E}_{\max } \mathrm{KCl}(\mathrm{g})$ & $0.44(0.08)$ & $0.47(0.18)$ & $0.55(0.13)$ & $0.44(0.1)$ \\
$\mathrm{E}_{\max } \mathrm{PE}(\mathrm{g})$ & $0.60(0.14)$ & $0.66(0.15)$ & $0.71(0.13)$ & $0.64(0.14)$ \\
$\mathrm{E}_{\max } \mathrm{ACh}(\%)$ & $98.43(3.01)$ & $65.71(11.14)^{\mathrm{a}}$ & $87.50(12.38)^{\mathrm{b}}$ & $82.91(12.28)^{\mathrm{a}, \mathrm{b}}$ \\
pEC50 & $6.77(0.07)$ & $6.28(0.10)^{\mathrm{a}}$ & $6.77(0.15)^{\mathrm{b}}$ & $6.43(0.12)$ \\
\hline
\end{tabular}

Data are presented as mean (standard deviation), $n=10 /$ group. $^{\mathrm{a}} p<0.05$ compared to normal group, ${ }^{\mathrm{b}} p<0.05$ compared to the OB group. All data were analyzed using one-way ANOVA followed by Tukey's post hoc test. OB: obese, $\mathrm{OB} / \mathrm{BB}$ : obese and bee bread $0.5 \mathrm{~g} / \mathrm{kg} /$ day, $\mathrm{OB} / \mathrm{OR}$ : obese and orlistat $10 \mathrm{mg} / \mathrm{kg} /$ day, $\mathrm{E}_{\max }$ : maximum relaxation, $\mathrm{KCl}$ : potassium chloride, $\mathrm{PE}$ : phenylephrine, $\mathrm{ACh}$ : acetylcholine, $\mathrm{pEC50}$ is the negative logarithm of the concentration of $\mathrm{ACh}$ that gives a half-maximal response. 


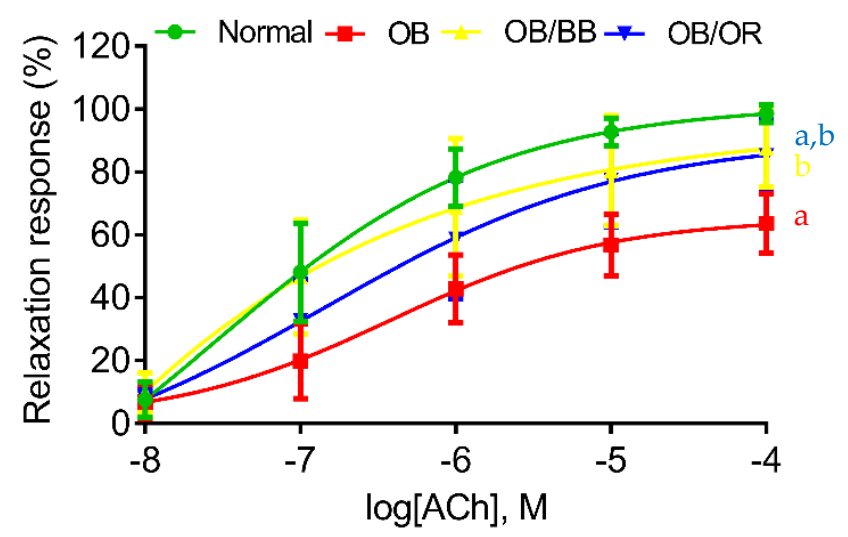

(A)

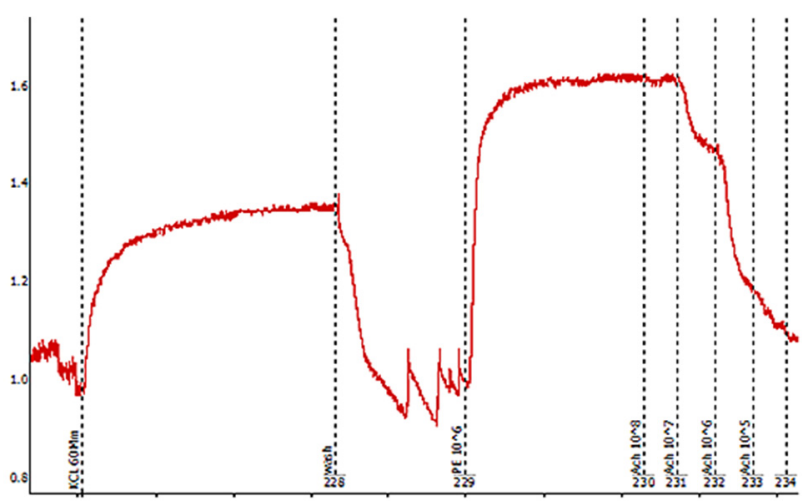

(B)

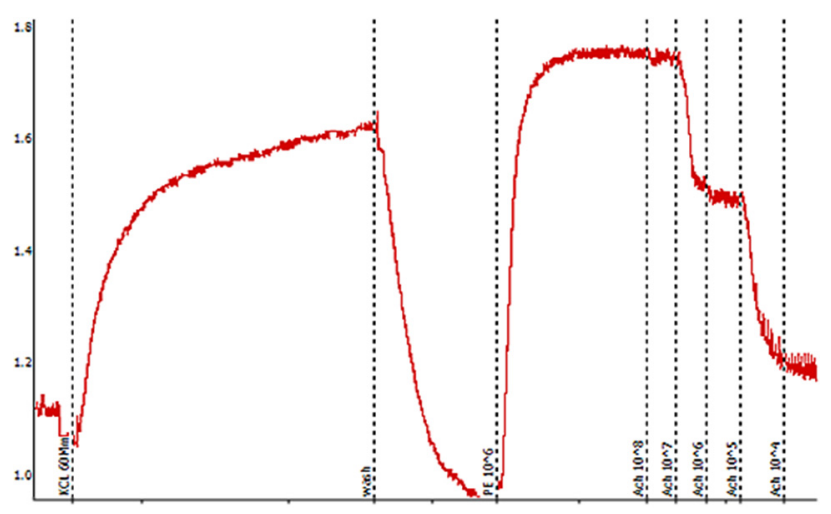

(D)

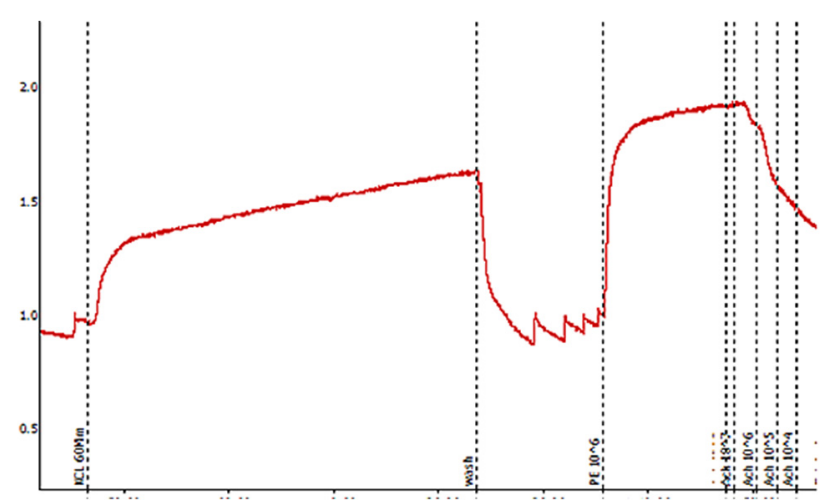

(C)

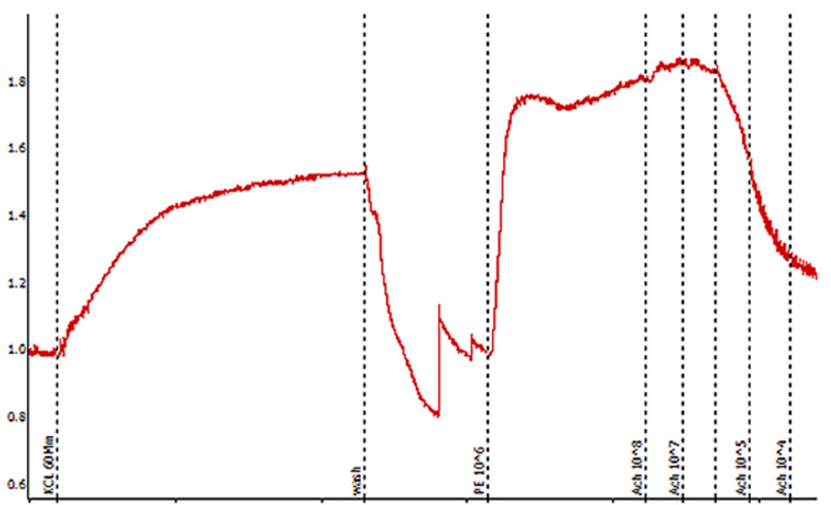

(E)

Figure 2. The vasorelaxant effect of bee bread in endothelium-intact thoracic aortic rings precontracted with phenylephrine $\left(10^{-6} \mathrm{M}\right)$. Fitted cumulative acetylcholine (ACh) dose-response curve is shown in (A), and schematic graphs of ACh-induced vasorelaxation activity from (B) normal, (C) OB, (D) OB/BB and (E) OB/OR groups are demonstrated. All values are presented as mean and standard deviation (A), $n=8 /$ group. Data were analyzed using nonlinear regression. ${ }^{\mathrm{a}} p<0.05$ compared to normal group, ${ }^{b} p<0.05$ compared to the OB group. OB: obese, OB/BB: obese and bee bread $0.5 \mathrm{~g} / \mathrm{kg} / \mathrm{day}$, OB/OR: obese and orlistat $10 \mathrm{mg} / \mathrm{kg} /$ day. 


\subsection{Effect of Bee Bread on Immunoexpression of eNOS and cGMP, and NO Level in the Aorta of Obese Rats}

To further confirm the participation of eNOS in endothelium-dependent vasorelaxation, we determined the levels of eNOS and cGMP proteins and NO levels in the aorta. As shown in Figure 3, the mean area for positive immune cells of eNOS (Figure 3A,C) and cGMP (Figure 3B,D) proteins and the level of aortic NO (Figure 3E) were decreased in the OB group when compared to the normal group. In contrast, the levels of eNOS and cGMP proteins and NO levels increased significantly in $\mathrm{OB} / \mathrm{BB}$ and $\mathrm{OB} / \mathrm{OR}$ groups when compared to the OB group.
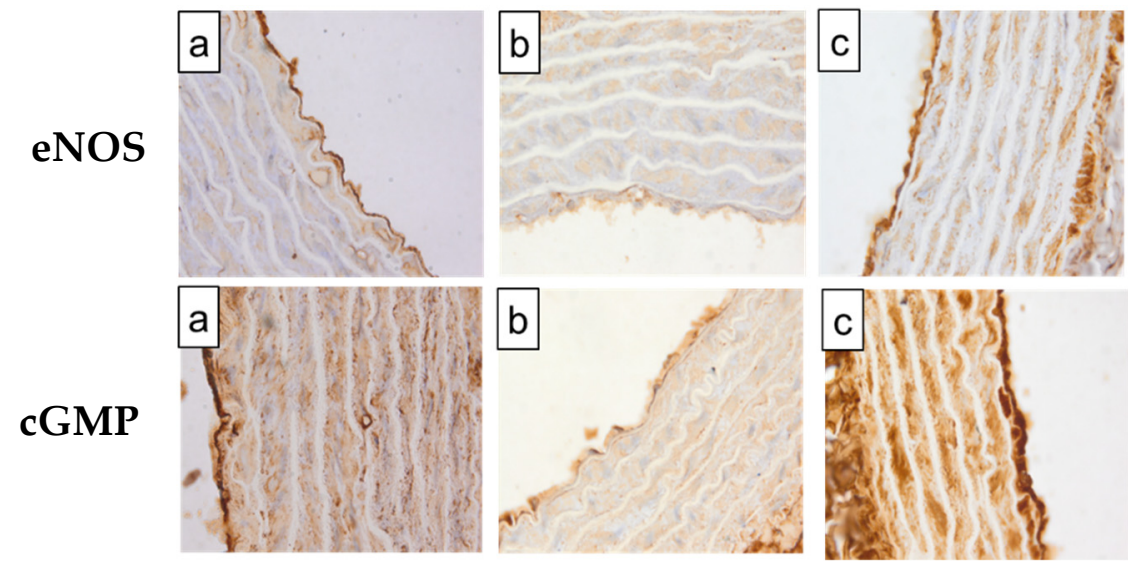

(A)

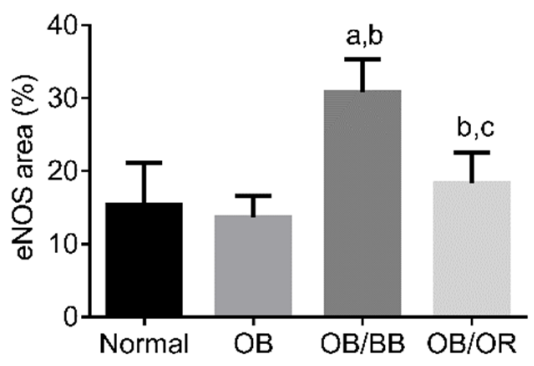

(B)

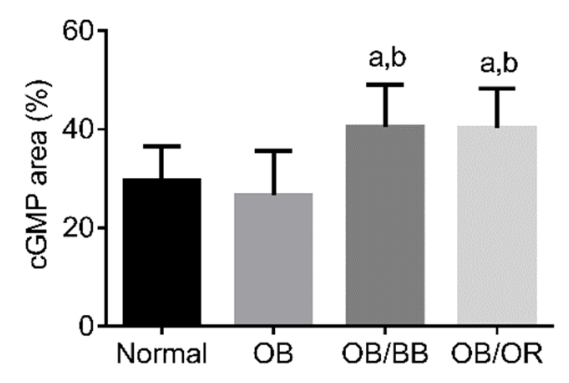

(C)
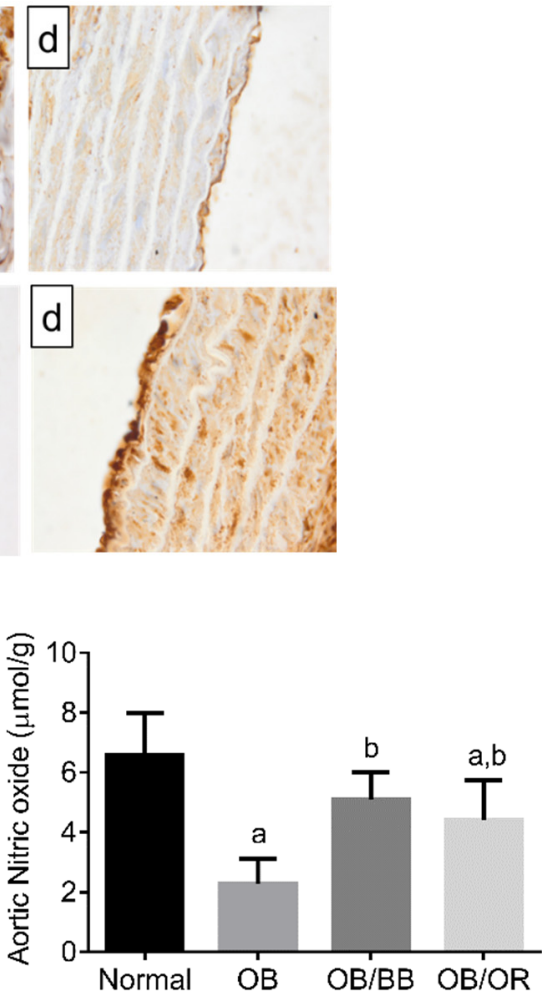

(D)

Figure 3. Representative photomicrographs from positive immunohistochemical staining of (A,B) eNOS and (A,C) cGMP area (brown staining, magnification $400 \times$ ), and (D) aortic NO level in the aorta of (a) normal (b) OB (c) OB/BB and (d) OB/OR groups, $n=6 /$ group. The quantitative positive staining area of eNOS and cGMP are shown in (B) and (C), respectively and expressed in percentage value. All data are presented as mean and standard deviation. ${ }^{\mathrm{a}} p<0.05$ compared to normal group, ${ }^{\mathrm{b}} p<0.05$ compared to the OB group, ${ }^{\mathrm{c}} p<0.05$ compared to the OB/BB group. All data were analyzed using one-way ANOVA followed by Tukey's post hoc test. OB: obese, OB/BB: obese and bee bread 0.5 g/kg/day, OB/OR: obese and orlistat $10 \mathrm{mg} / \mathrm{kg} /$ day, eNOS: endothelial nitric oxide synthase, cGMP: cyclic guanosine monophosphate, NO: nitric oxide.

\subsection{Effect of Bee Bread on Morphology of Aorta in Obese Rats}

Figure 4 demonstrates the representative histological findings of H\&E (Figure 4A,B) and VVG (Figure 4C)-the stained aorta and the morphometric analysis from H\&E-stained aorta from each experimental group (Figure 5). Microscopic changes of the H\&E-stained aorta revealed the presence of a significantly thickened aortic wall in the OB group, which was associated with significantly thicker tunica intima and adventitia layers compared to the normal group. These effects were also found to be associated with a significant increase in wall thickness per lumen ratio in the OB group compared to the normal group. Treatment with BB and orlistat significantly restored all these changes with an observation of a significant decrease in the aortic wall thickness, including tunica intima and adventitia, 
compared to the OB group. The VVG-stained aorta of the normal group demonstrated the presence of linear and homogenous lining of the elastic lamella in the tunica media. Meanwhile, the VVG-stained aorta of the OB group showed architecture characteristic of irregularity and tortuous elastic lamellae in the tunica media, associated with the presence of rough endothelial surface compared to the normal group, and the lining of elastic lamellae seems to be markedly improved in the aortas of the OB/BB and OB/OR groups when compared to the $\mathrm{OB}$ group.

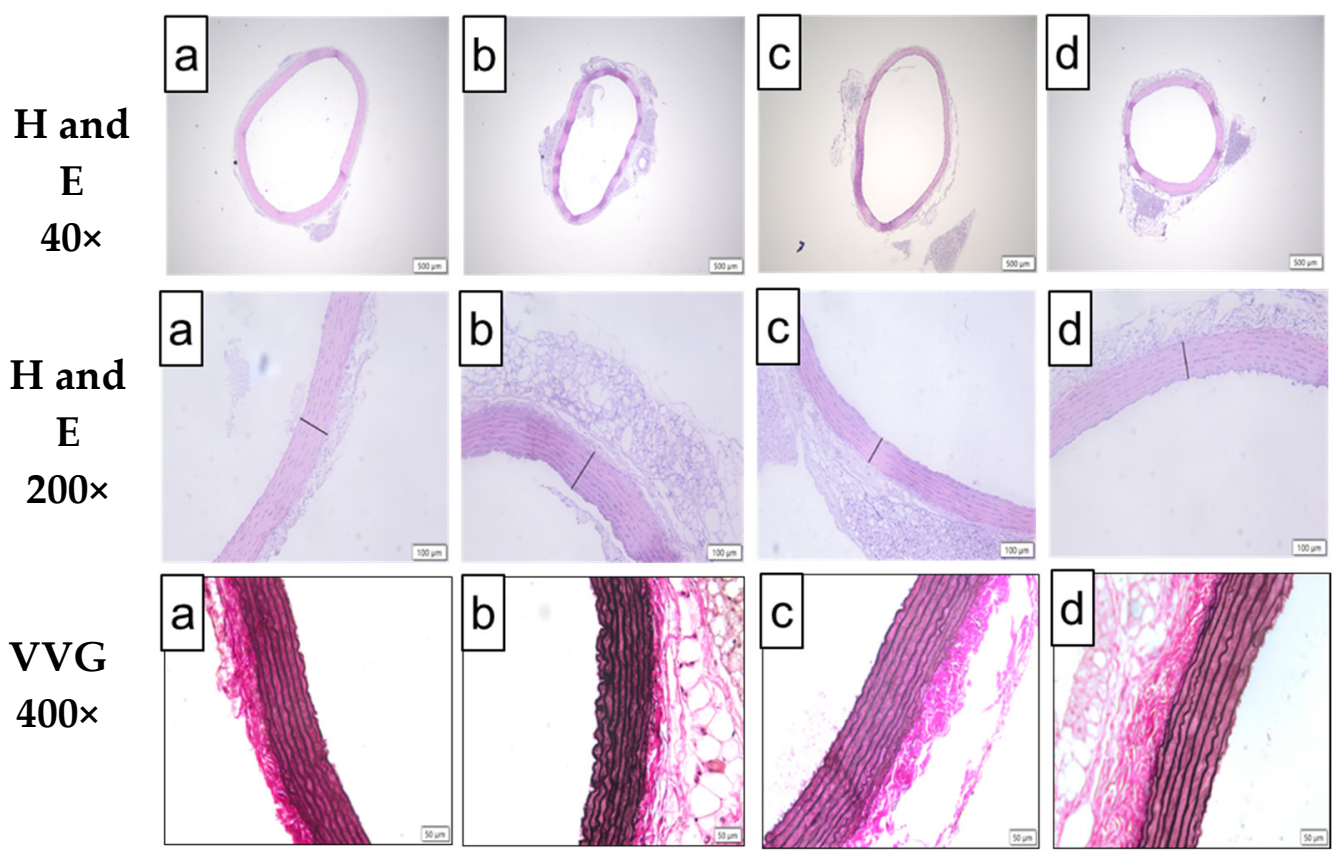

Figure 4. Representative photographs of aortic arch sections stained with H\&E (magnification $=40 \times$ and 200 $\times$, scale bar $=500 \mu \mathrm{m}$ and $100 \mu \mathrm{m}$ ) and VVG (magnification $400 \times$, scale bar $=50 \mu \mathrm{m}$ ) from (a) normal, (b) OB, (c) OB/BB and (d) OB/OR groups. H\&E staining showed the presence of normal aorta lining in the normal group, while a thicker aorta was observed in the OB group compared to the normal group. The thickness of the aorta was also markedly reduced in $\mathrm{OB} / \mathrm{BB}$ and $\mathrm{OB} / \mathrm{OR}$ groups compared to the OB group. VVG staining showed the presence of wavy, irregular and tortuous elastic lamella in the $\mathrm{OB}$ group and the internal lamella lining was homogenously improved in (c) and (d) groups compared to (b) OB: obese, OB/BB: obese, and bee bread $0.5 \mathrm{~g} / \mathrm{kg} /$ day, OB/OR: obese and orlistat $10 \mathrm{mg} / \mathrm{kg} /$ day, H\&E: hematoxylin and eosin, VVG: Van Verhoef Gielson. 


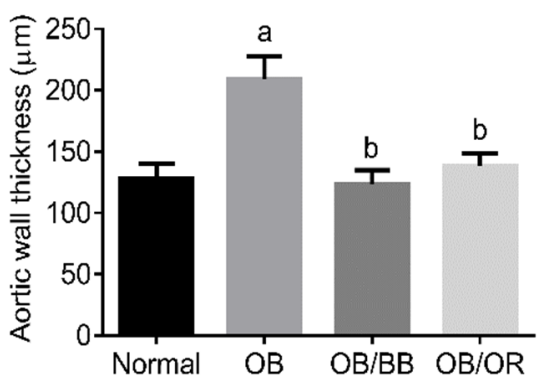

(A)

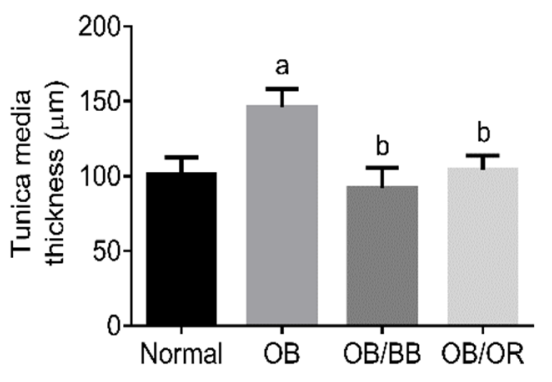

(B)

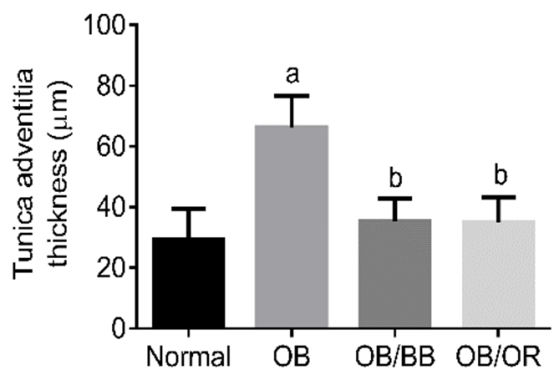

(C)

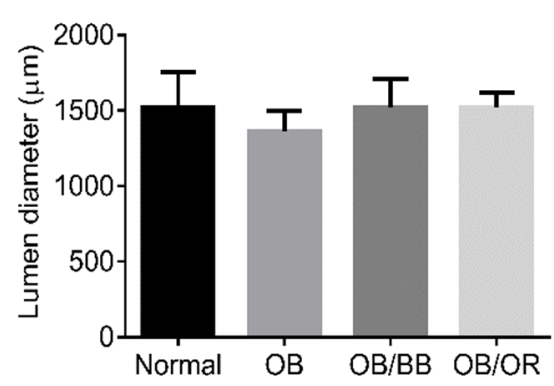

(D)

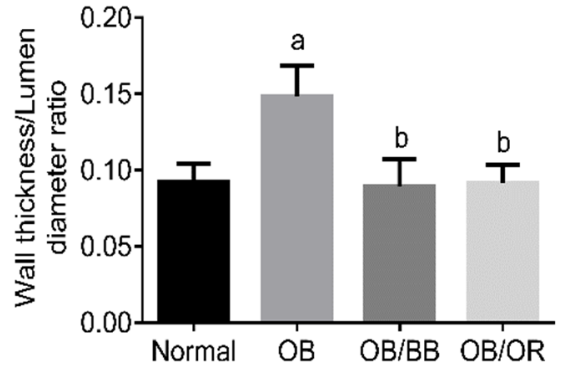

(E)

Figure 5. Morphometric analysis of H\&E stained aorta from each experimental group. Values are mean and standard deviation, $n=10$ /group. Thickness of (A) aortic wall, (B) tunica media, and (C) tunica adventitia, (D) lumen diameter and (E) ratio of wall thickness per lumen diameter of the thoracic aorta. OB: obese, OB/BB: obese and bee bread $0.5 \mathrm{~g} / \mathrm{kg} / \mathrm{day}$, $\mathrm{OB} / \mathrm{OR}$ : obese and orlistat $10 \mathrm{mg} / \mathrm{kg} /$ day. ${ }^{\mathrm{a}} p<0.05$ compared to normal group, ${ }^{\mathrm{b}} p<0.05$ compared to the OB group. All data were analyzed using one-way ANOVA followed by Tukey's post hoc test.

\subsection{Mineral Composition of Bee Bread}

The bee bread used in the present study showed a broad spectrum of mineral composition. Our result demonstrates that the major electrolytes, which are abundantly present in bee bread, are potassium $(7323.04 \mathrm{mg} / \mathrm{kg})$, magnesium $(1530.87 \mathrm{mg} / \mathrm{kg})$ and calcium $(1108.48 \mathrm{mg} / \mathrm{kg})$, followed by sodium $(252.73 \mathrm{mg} / \mathrm{kg})$. In addition, it also possesses trace minerals, namely: iron $(56.58 \mathrm{mg} / \mathrm{kg})$, zinc $(42.36 \mathrm{mg} / \mathrm{kg})$, copper $(11.05 \mathrm{mg} / \mathrm{kg})$ and selenium $(0.13 \mathrm{mg} / \mathrm{kg})$ (Table 3$)$.

Table 3. Mineral and vitamin contents of bee bread.

\begin{tabular}{cc}
\hline Minerals & Composition $\mathbf{( m g} / \mathbf{k g})$ \\
\hline Calcium & 1108.48 \\
Copper & 11.05 \\
Iron & 56.58 \\
Magnesium & 1530.87 \\
Potassium & 7323.04 \\
Selenium & 0.13 \\
Sodium & 252.73 \\
Zinc & 42.36 \\
\hline
\end{tabular}

\section{Discussion}

Our study demonstrated that bee bread treatment at $0.5 \mathrm{~g} / \mathrm{kg} /$ day for 6 weeks exerted a therapeutic effect on obesity-induced impairment in ACh-mediated vasorelaxation response, in addition to ameliorating aortic inflammation and structural changes, obesity index, hyperlipidemia and atherogenic ratios. Our study also has pointed to the mechanistic role of aortic eNOS/NO/cGMP-signaling pathway in obesity-induced impairment in ACh-mediated vasorelaxation response. 
Hyperlipidemia is one of the features of obesity, leading to the development and progression of vascular dysfunction that could be attributed to atherosclerosis [23]. Excessive intake of diets containing high dietary fat contributes to fat accumulation in the body and results in obesity. We used the Lee obesity index as a tool to determine obesity, where a value higher than 315 was categorized as obese [24]. The present findings showed that chronic intake of HFD for 12 weeks caused a large accumulation of body fat mass, as evident in a significant increase in Lee obesity index demonstrated in the OB group. The increase in Lee obesity index contributed to the increased fat accumulation in the body. In the present study, the continuous HFD ingestion may have resulted in enormous TG production and storage in the adipose tissue, increased sizes and number of adipocytes, and increased adiposity. This was supported by the higher atherogenic ratios (AI, CRI-1 and CRI-11), representing a higher risk of developing atherosclerosis [25]. The weight-reducing and cholesterol-lowering effects of bee bread observed in the present study agree with our previous study [22]. The significant reduction in lipid fractions found in the OB/BB group may be related to the presence of active polyphenols, such as caffeic and ferulic acids, which have lipid-lowering effects, as demonstrated in previous studies [22,26,27]. Moreover, the mechanism by which bee bread reduced the serum non-HDL lipids concentration may be due to the action of saponin in the bee bread because saponin has been reported to bind to dietary fat constituents, and in turn, increase fat excretion in feces [28]. The significant reductions in TC, TG and LDL levels, with an increase in HDL level in the $\mathrm{OB} / \mathrm{OR}$ group, are consistent with a previous study that administered $30 \mathrm{mg} / \mathrm{kg}$ orlistat, a potent gastropancreatic lipase inhibitor, for 8 weeks in an obese rat model [29]. Orlistat has been reported to increase the paraoxonase activity of HDL particles, hence, increase its antioxidant activity by preventing the oxidation of lipid peroxidation products, particularly the pro-atherogenic LDL-cholesterol [30]. Therefore, both bee bread and orlistat could mitigate atherosclerosis progression by targeting hyperlipidemia.

The initiation of vascular dysfunction is not only caused by increased lipid concentration but also due to a cascade of inflammatory processes, which is a crucial factor for atherosclerosis progression manifested by increased cytokine release [31]. TNF- $\alpha$ is a potent activator for NF- $\mathrm{k} \beta$, which is crucial for the generation of other proinflammatory markers, such as the leukocyte adhesion molecules and chemokines, which can further initiate vascular dysfunction [6]. In the present study, we quantified proinflammatory TNF- $\alpha$ and NF- $\kappa \beta$ in the aorta, which are important mediators of atherogenesis, together with the level of the anti-inflammatory cytokine, IL-10. In normal physiological conditions, NF-k $\beta$ is sequestered by $\operatorname{Ik} \beta \alpha$, while increased TNF- $\alpha$ causes the degradation of $\operatorname{Ik} \beta \alpha$, hence allowing the translocation of NF- $\kappa \beta$ into the nucleus where it initiates the expression of target genes encoding for leukocyte adhesion molecule and chemokine release [32]. The presence of inflammation, as shown by the significantly elevated levels of aortic TNF- $\alpha$ and NF- $\kappa \beta$ and decreased aortic IL-10 level in the OB group, is consistent with the finding in the testis of the obese rat model [33]. Meanwhile, both bee bread and orlistat significantly suppressed the increased aortic TNF- $\alpha$ and NF- $\kappa \beta$ levels, indicating their anti-inflammatory actions, which are consistent with previous findings in the kidney of obese rats [34]. The improvement of these inflammatory markers in the OB/BB group may be related to the inhibition of NF- $\mathrm{k} \beta$ activity and enhancing the activity of IL-10 by the flavonoids present in the bee bread, such as isorhamnetin kaempferol and quercetin [35]. Our previous study demonstrated that orlistat exerted anti-inflammatory properties by significantly suppressing the increase in expression of NF- $\kappa \beta$ derived pro-atherogenic markers of adhesion molecules, such as vascular cell adhesion molecule (VCAM-1) and intracellular cell adhesion molecule (ICAM-1) [36]. Therefore, NF- $\mathrm{KB}$ becomes an interesting therapeutic target to combat the progression of atherosclerosis. However, it is unclear how bee bread and orlistat could ablate the TNF- $\alpha / N F-\kappa \beta$ signaling and thus require a detailed study to determine their exact molecular mechanisms of action.

The endothelium is a single-cell receptor-rich lining of the inner layer of the intima that plays a critical role in the regulation of vascular tone, and thus, is a primary target for 
vasodilatory action [37]. Endothelial damage could contribute to developing atherosclerosis and loss of endothelial-dependent vasorelaxation [38]. Our findings revealed an impairment in the dose-dependent ACh-mediated vasorelaxation of aortic rings in the $\mathrm{OB}$ group ( $\mathrm{E}_{\max } 65.71 \%, \mathrm{p}_{50} 6.28$ ) compared to the normal group ( $\mathrm{E}_{\max } 98.43 \%, \mathrm{p}_{50} 6.77$ ), indicating the failure of endothelial function to maintain the vascular tone. Meanwhile, the endothelial-dependent vasorelaxation of the aortic rings in the $\mathrm{OB} / \mathrm{BB}$ and $\mathrm{OB} / \mathrm{OR}$ groups showed significant improvements, in a concentration-dependent manner, compared to the OB group, which may indicate the improvement of endothelial function. In the present study, bee bread has demonstrated its ameliorative effect on the impairment of ACh-induced endothelium-dependent relaxation that is comparable to orlistat, without any changes in maximal relaxation towards $\mathrm{KCl}$ and PE. Several mechanisms may account for developing endothelial dysfunction in obesity. These include the presence of pro-atherogenic LDL cholesterol in the subendothelial region that triggers an aortic inflammatory reaction by activating the TNF- $\alpha / \mathrm{NF}-\mathrm{K} \beta$ pathway, hence accelerates the progression of atherosclerosis [39]. The ongoing inflammatory process involves the migration and proliferation of the vascular smooth muscle cell [40] that subsequently increases the interlaminar space, extracellular matrix content and further destroys the normal alignment of elastic fibers of tunica media as demonstrated in VVG-stained aorta in the OB group. Therefore, these changes could then affect the structural integrity of the vessel, which subsequently impairs the vasodilatory response. On the other hand, the changes in the lumen diameter of the vessels can also influence the tissue perfusion and debilitate the response of vessels towards vasodilators and vasoconstrictors [41]. Therefore, we speculated that the increase in the atherogenic LDL cholesterol, aortic TNF- $\alpha$ /NF- $\kappa \beta$ activation, thicken aortic wall, and distorted elastic lamellae in the tunica media found in the $\mathrm{OB}$ group might be the factors that contributed to the impairment of the structural integrity of the aorta and therefore, impaired its endothelial-dependent vasorelaxation response. Treatment with bee bread and orlistat, however, ameliorated these morphological changes. The restored alignment of the elastic lamellae in the treatment groups, when compared to the OB group, might imply the ameliorative effects of bee bread and orlistat, hence improved the endothelial-dependent vasorelaxation response in our obesity model. This could be due to its hypolipidemic and anti-inflammatory effects, which need further study to determine the exact molecular mechanism of action.

Studies have shown that the relaxation responses of the vessels are primarily attributed to the presence of NO, a potent vasodilator, which is primarily generated by eNOS in the endothelium $[39,42]$. The generated NO diffuses from the endothelial layer to the smooth muscle, where it activates soluble guanylyl cyclase (sGC) and converts guanosine triphosphate (GTP) to cGMP, leading to smooth muscle relaxation [43]. Hence, the lower level of NO and immuno-expressions of eNOS and cGMP proteins which are similar to previous studies [44,45], could explain the observed impairment of vasorelaxation response found in the OB group. However, bee bread and orlistat treatments ameliorated these changes. The level of NO is increased following the phosphorylation of eNOS, which results in its functional activity. However, in a hyperlipidemic state, the level of phosphorylated eNOS is reduced by the action of oxidized pro-atherogenic LDL that inhibits the eNOS coupling and activation [46]. Therefore, it is plausible to suggest that bee bread and orlistat improved the NO level by enhancing eNOS expression, which in turn improved the vasorelaxation response to $\mathrm{ACh}$ in the present study. Studies have found that several natural products could also increase eNOS activity and, therefore, increase the vasorelaxant responses [47,48]. For example, white tuber extract has been reported to improve relaxation response to ACh and increase eNOS expression via improvement of NO/cGMP-signaling pathway in aortic tissue of rats fed with HFD [14]. The enhancement of eNOS expression in the $\mathrm{OB} / \mathrm{BB}$ group could also be attributed to the presence of active compounds in bee bread, which stimulates the phosphorylation of eNOS, thereby increase its activation and production of functional NO. 
The bee bread that was used in our study contains a broad spectrum of trace minerals (iron, zinc, copper and selenium) and electrolytes (calcium, potassium, magnesium and sodium). These minerals are essential as they act as cofactors and mediators for physiological and biochemical functions in the body. Hence, we speculate that the presence of broad-spectrum minerals in the bee bread may also contribute to the improvement of vascular reactivity in this obesity model. For instance, both copper and zinc are involved as ligands in the superoxide dismutase (SOD1) system, which catalyzes the dismutation of highly toxic superoxide radicals into oxygen and hydrogen peroxide [49]. The improvement of the structure and function of the aorta in rats treated with bee bread in our study may also be related to the presence of this oxidoreductase enzyme via its action in reducing the pro-atherogenic oxidized LDL. Magnesium has a regulatory role on blood pressure since it can improve the vascular tone and mediate vascular smooth muscle contraction. Studies have shown that maintaining the magnesium level in the body can improve vascular reactivity and impede endothelial dysfunction, as well as prevent the associated cardiovascular health-related problems, such as obesity, hypertension and stroke [50]. Taken together, we hypothesize that bee bread treatment ameliorates the impaired AChmediated vasorelaxation in the aorta of obese rats via eNOs/NO/cGMP pathway, which was comparable with orlistat treatment (Figure 6).

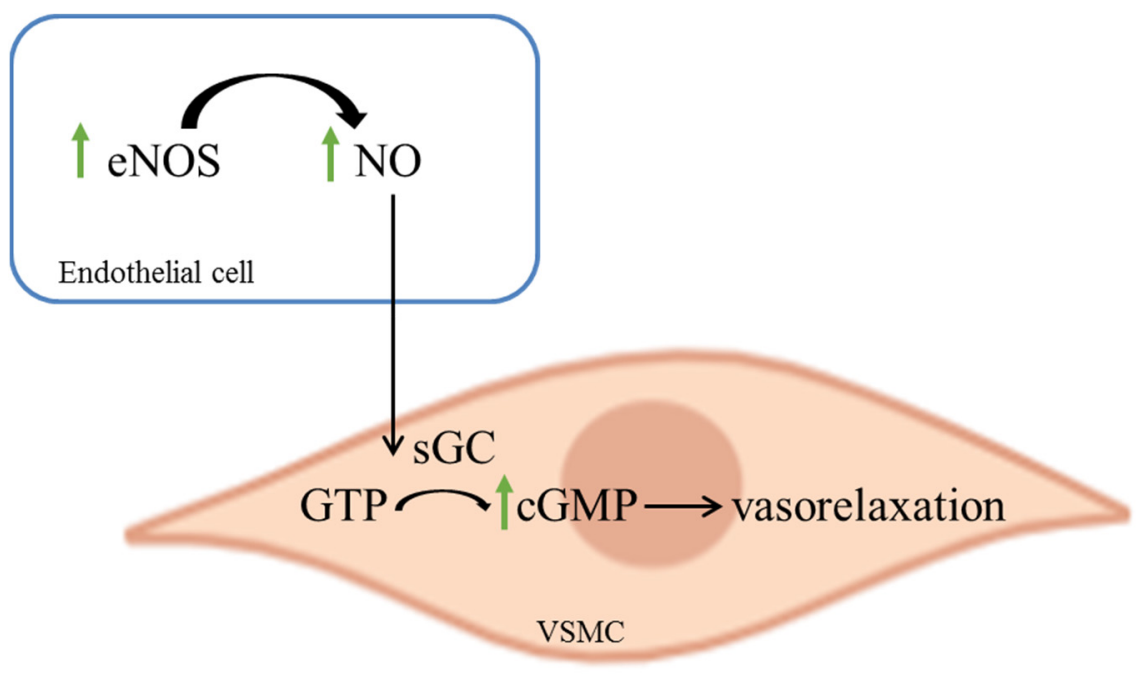

Figure 6. Schematic diagram of the mechanism of bee bread (green arrowhead) induced vasorelaxation in the isolated aorta of obese rats. eNOS: endothelial nitric oxide synthase, NO: nitric oxide, GTP: guanosine triphosphate, cGMP: cyclic guanosine monophosphate, VSMC: vascular smooth muscle cell.

\section{Materials and Methods}

\subsection{Chemical and Drugs}

Sodium chloride, potassium chloride, calcium chloride dehydrate, magnesium sulfate anhydrous and potassium dihydrogen phosphate were purchased from Merck (Emsure ${ }^{\circledR}$ Merck KGaA, Darmstadt, Germany), while sodium hydrogen carbonate was purchased from Riedel-de Haën (Seelze, Germany). D (+)-Glucose monohydrate was obtained from $\mathrm{HmbG}^{\circledR}$ Chemicals (Hamburg, Germany), Acetylcholine chloride from Nacalai Tesque, Inc. (Kyoto, Japan) and (R)-Phenylephrine Hydrochloride from TCI Development Co., Ltd. (Shanghai, China). All other reagents and solvents were analytical grade.

\subsection{Preparation of Bee Bread}

Bee bread was purchased from a local beekeeper farm (Mentari Technobee PLT), Kelantan, Malaysia. Fresh bee bread was dried using a food dehydrator at $35^{\circ} \mathrm{C}$ until a constant weight was achieved, followed by crushing in an industrial blender into powder form. The powder was kept at $-20^{\circ} \mathrm{C}$ until further use. 


\subsection{Animals and Diet}

Forty male Sprague-Dawley rats (weighing 180-230 g, aged 8-10 weeks old) were purchased from the Animal Research and Service Centre, Universiti Sains Malaysia. They were housed in individual cages with a controlled temperature at $22 \pm 2{ }^{\circ} \mathrm{C}$, relative humidity $60-70 \%$, and $12 \mathrm{~h}$ light/dark cycle. All rats were given a normal chow diet and water ad libitum during one week of the acclimatization period. The rats were fed either a normal diet (Altromin Spezialfutter GmbH and Co. KG, Lage, Germany) or a high-fat diet (HFD), which was prepared according to our previous study [22]. The normal diet comprised of $64 \%$ carbohydrate, $24 \%$ protein, and $12 \%$ fat, which contributes to $31.8 \mathrm{kcal} / \mathrm{g}$, while the HFD comprised of $46 \%$ carbohydrate, $12 \%$ protein and $31 \%$ fat, which contribute to $51.65 \mathrm{kcal} / \mathrm{g}$.

\subsection{Experimental Design}

The study is divided into two phases. In phase 1 , the rats were randomly divided into two groups, i.e., a normal group $(n=10)$ and a high-fat diet (HFD) group $(n=30)$. The rats in the normal group received a normal chow diet, while rats in the HFD group were administered with HFD for 6 weeks to induce obesity characterized by a high Lee obesity index of more than 315 . In phase 2, which also lasted for 6 weeks, the normal group continued to receive a normal chow diet. Obese rats from phase 1 were subjected to treatment phase with continuous administration of HFD either with distilled water (OB group), bee bread at $0.5 \mathrm{~g} / \mathrm{kg} /$ day $(\mathrm{OB} / \mathrm{BB}$ group), or orlistat at $10 \mathrm{mg} / \mathrm{kg} /$ day (OB/OR group) via oral gavage. The corrected amount of bee bread and orlistat were based on the respective weight of the rats. Both bee bread and orlistat were separately suspended in $1 \mathrm{~mL}$ of distilled water before being administered to the rats daily. Bodyweight and food intake were determined once a week and every day, respectively, during the entire experimental period. All animal procedures were handled following the National Institute of Health Guide for the Care and Use of Laboratory Animals, and USM animal ethics approved the study (USM/IACUC/2018/(113)(933)). All efforts were made to minimize animal suffering. At the end of the experimental period, all rats were sacrificed after being euthanized with ketamine $90 \mathrm{mg} / \mathrm{kg}$ and xylazine $5 \mathrm{mg} / \mathrm{kg}$. Central blood was collected from the posterior vena cava for serum analysis. The thoracic aorta was immediately excised for analysis on vascular reactivity. The aortic arch was homogenized with $10 \%$ $0.1 \mathrm{M}$ phosphate-buffered saline $(w / v)$ for biochemical analysis, and the abdominal aorta was divided into sections for histological analysis.

\subsection{Measurement of Obesity Parameters}

Lee obesity index was determined following a previously described method, and a value $>315$ was considered obese [24]. The Lee index was calculated by dividing the cube root of the bodyweight (gram) by the naso-anal length $(\mathrm{cm})$. The obtained result was multiplied by 1000 .

\subsection{Measurement of Lipid Profile and Atherogenic Ratios}

The collected blood was allowed to stand for $2 \mathrm{~h}$ at room temperature, and the serum was separated by centrifugation at $4000 \times g$ for $15 \mathrm{~min}$. Total cholesterol (TC) and triglyceride (TG) were measured by an enzymatic-colorimetric method using Architect $\mathrm{c}$ total cholesterol and triglyceride kits (ARCHITECT c kit, Abbott, IL, USA). The low-density lipoprotein (LDL) was calculated using the equation: LDL $(\mathrm{mg} / \mathrm{dL})=\mathrm{TC}-\mathrm{HDL}-(\mathrm{TG} / 5)$ [51]. Highdensity lipoprotein (HDL) was determined by Biosino Direct HDL-Cholesterol reagent kit (Biosino Bio-Technology and Science Inc., Beijing, China). Atherogenic ratios are predictive factors for atherosclerosis and were calculated as follows:

Atherogenic index $=($ TC-HDL $) /$ HDL [52];

Castelli's risk index (CRI-I) $=$ TC /HDL [53];

Castelli's risk index $($ CRI-II $)=$ LDL/HDL [25]. 


\subsection{Determination of Aortic Inflammatory Markers}

The aortic homogenate was used to quantify proinflammatory (TNF- $\alpha$ and NF- $k \beta$ ) and anti-inflammatory cytokine (interleukin-10, IL-10), which may contribute to the presence of vascular damage by adopting rat enzyme-linked immunosorbent assay (ELISA) supplied by Qayee-Bio (Shanghai, China) according to the manufacturer's protocol. The absorbance value was read at $450 \mathrm{~nm}$ wavelength.

\subsection{Determination of Aortic NO Level}

$\mathrm{NO}$ was quantified in aortic homogenate using a NO assay detection kit (Elabscience, Wuhan, China) according to the manufacturer's instructions. Since NO has a short half-life, the kit measures the levels of NO metabolites, i.e., nitrate and nitrite. Following a color change at room temperature, the absorbance value was determined using a microplate reader at $550 \mathrm{~nm}$ wavelength. Sodium nitrite was used as a standard. Total NO for each sample was normalized with protein concentration and expressed as $\mu \mathrm{mol} / \mathrm{g}$ protein.

\subsection{Preparation of Aorta and Measurement of Vascular Reactivity}

The thoracic aorta was dissected out and transferred into a petri-dish containing ice-cold, pre-carbonated $\left(95 \% \mathrm{O}_{2}, 5 \% \mathrm{CO}_{2}\right)$ Krebs-Henseleit solution $(118 \mathrm{mM} \mathrm{NaCl}$, $4.7 \mathrm{mM} \mathrm{KCI}, 1.18 \mathrm{mM} \mathrm{MgSO} 4 \cdot 7 \mathrm{H}_{2} \mathrm{O}, 1.2 \mathrm{mM} \mathrm{KH}_{2} \mathrm{PO}_{4}, 2.0 \mathrm{mM} \mathrm{CaCl} \cdot 2 \mathrm{H}_{2} \mathrm{O}, 25 \mathrm{mM}$ $\mathrm{NaHCO}_{3}$ and $5.5 \mathrm{mM}$ D-glucose, $\mathrm{pH}$ 7.4) [54]. The aorta was carefully handled and removed from adhesive fat and connective tissue before being divided into three segmental rings, approximately $5 \mathrm{~mm}$ in size. Individual rings of the aorta were inserted with two stainless steel wires into the aortic lumen and bathed in a prewarmed $\left(37^{\circ} \mathrm{C}\right)$ tissue bath chamber containing $10 \mathrm{~mL}$ of Krebs-Henseleit solution and connected to an Automatic organ bath (PanLab. LE01026, Panlab, MA, USA) through a force transducer. The tissue bath containing Krebs-Henseleit solution was continuously aerated with $95 \% \mathrm{O}_{2}$ and $5 \% \mathrm{CO}_{2}$ to maintain the $\mathrm{pH}$ of 7.4. Isometric tension of $1 \mathrm{~g}$ was applied to the aorta for $45 \mathrm{~min}$ during the equilibrium phase. The tension was adjusted as required, and the Krebs-Henseleit solution was changed every $20 \mathrm{~min}$. After equilibrium, the aortic ring was challenged with $60 \mathrm{mM} \mathrm{KCl}$ to obtain reference contraction. Thereafter, the aortic rings were precontracted with PE $10^{6} \mathrm{M}$ followed by cumulative concentrations of $\mathrm{ACh}$, after which the maximum contraction of PE $10^{6} \mathrm{M}$ had reached its level. The aortic relaxation by cumulative addition of ACh was performed with intact endothelium to investigate the endothelium-dependent vasorelaxation. All changes in isometric tension were detected with a force transducer and recorded using LabChart ${ }^{\circledR}$ Reader. The vasorelaxation response was calculated in percentage of the contraction produced by $\mathrm{PE}$ as $\mathrm{E}_{\max }$. Maximal contractions of aortic rings toward $\mathrm{KCl}$ and $\mathrm{PE}$ were also expressed in percentage.

\subsection{Immunohistochemistry}

The paraffin-embedded aortic segment was sectioned at $5 \mu \mathrm{m}$ thickness onto a silanecoated slide (microslides, Muto Pure Chemicals Co., Ltd., Tokyo, Japan). After being placed on a hot plate at $60^{\circ} \mathrm{C}$ for $10 \mathrm{~min}$, the slides were hydrated with different concentrations of ethanol. Antigen retrieval was performed by placing the slides into a pressure cooker filled with a tris-EDTA buffer with $0.05 \%$ tween- 20 (pH 9.0) for $3 \mathrm{~min}$. The sections were immersed in 3\% hydrogen peroxide for $5 \mathrm{~min}$ to block the endogenous peroxidase before incubating with polyclonal primary antibodies for cGMP (1:100, Frieldwelt, USA) and eNOS (1:20, CloudClone, China) in a humidified chamber overnight. Afterward, the sections were incubated with Dako Envision ${ }^{\mathrm{TM}}+$ System/HRP-labeled polymer (Dako North America, Inc., Carpinteria, CA, USA) containing goat anti-rabbit secondary antibody for $1 \mathrm{~h}$. Specific labeling of the antigen was visualized by diaminobenzidine (Dako Liquid DAB+ Substrate Chromogen System, Dako North America, Inc.). The slides were counterstained with hematoxylin solution, and the positive immunostaining areas were examined under a light microscope (Leica, Wetzlar, Germany). Photographs were taken in five non-overlapping fields in each paraffin block for each rat ( $n=6$ /group) using $100 \times$ 
objective. The mean of the stained area of the five fields was used as a representative for an individual rat and quantified using ImageJ software (ImageJ, NIH, Bethesda, MD, USA).

\subsection{Aorta histological Analysis}

Isolated aorta from each group was fixed in $10 \%$ formalin $(v / v)$ for $24-48 \mathrm{~h}$. The tissue was excised and processed using an automated tissue processor (Leica, Wetzlar, Germany) and subsequently embedded in Paraplast (Sigma-Aldrich, St. Louis, MO, USA). Afterward, the tissue was sectioned at $5 \mu \mathrm{m}$ thickness using a microtome (Leica RM2235, Walldorf, Germany) before being stained with hematoxylin and eosin (H\&E), and Verhoeff-Van Gieson's (VVG) method, respectively [37]. H\&E-stained aortic sections were used to measure the thicknesses of the aortic wall, tunica media, tunica adventitia (without the perivascular adipose tissue), and lumen diameter. Meanwhile, VVG staining was performed to compare the lining of internal lamella in the tunica media layer. For histomorphometry of the H\&E-stained aorta, photographs were taken from five different non-overlapping fields ( $n=10$ /group) using a $40 \times$ objective. Each photograph was used for the morphometry analysis using the straight segmented or freehand lines tools of the cell sense system in Image analyzer (Olympus, Tokyo, Japan). The mean value of the five fields was used as a representative for each rat.

\subsection{Mineral Analysis of Bee Bread}

Thirty grams of powdered bee bread was utilized for analysis of the mineral composition. Microwave-assisted extraction was performed using a Milestone microwave laboratory system (MLS-1200 Mega, Gemini BV, Apeldoorn, The Netherlands). The yield stock solution was used for the analysis of mineral composition by using inductively coupled plasma mass spectrometry (ICP-MS) (Elan 9000, PerkinElmer Instrument, Waltham, MA, USA).

\subsection{Statistical Analysis}

All data were analyzed using GraphPad Prism version 6 (GraphPad Software Inc., San Diego, CA, USA). Shapiro-Wilk and D'Agostino-Pearson's omnibus tests were used to confirm that all data were normally distributed and homogenous, respectively. Then, One-way analysis of variance (ANOVA) followed by Tukey's post hoc test was used for the determination of significant differences between the experimental groups, and the results were expressed as mean (standard deviation). Differences with a $p$ value of $<0.05$ were considered statistically significant. Relaxation responses were expressed as a percentage decrease of the maximal PE contraction. The cumulative dose-dependent curve was plotted on the application of sigmoidal curve fitting and nonlinear regression as maximum relaxation $\left(\mathrm{E}_{\mathrm{max}}\right)$ and $\mathrm{pE}_{50}$ (negative logarithm of the concentration of $\mathrm{ACh}$ that was needed to produce $50 \%$ of the maximum aortic relaxation response).

\section{Conclusions}

Bee bread treatment at $0.5 \mathrm{~g} / \mathrm{kg} /$ day for 6 weeks following obesity induction significantly improved the lipid profile, atherogenic ratios, aortic inflammatory markers and the morphological changes of the aorta in rats. These changes cumulatively resulted in the ameliorative effect of bee bread on impaired vasorelaxation response to ACh, which could involve eNOS/NO/cGMP-signaling pathway (Figure 6). Further studies are required to determine its exact molecular mechanism of action, in addition to the possibility of mimicking the actions of statins in inhibiting HMG-CoA reductase. In addition, further study is also suggested to evaluate the possible effects of bee bread and orlistat on these parameters in rats fed with a normal diet. 
Author Contributions: Conceptualization: M.M.; methodology: M.M. and W.S.W.G.; formal analysis: Z.A.O., A.C.R. and M.M.; investigation: Z.A.O., Z.Z., J.B.S., V.U.N. and A.C.R.; writing-original draft preparation: Z.A.O.; writing—review and editing: Z.A.O., Z.Z., J.B.S., V.U.N., A.C.R., W.S.W.G., and M.M.; visualization: Z.A.O.; supervision: W.S.W.G. and M.M.; funding acquisition: Z.A.O., Z.Z., and M.M. All authors have read and agreed to the published version of the manuscript.

Funding: This study was financially supported by USM research project no 1001.PPSP.8012378, approved on 14 February 2020. The authors also would like to thank USM for awarding the PPSP Graduate Development Incentive Fund (TIPPS), approved on 15 July 2019 for the analysis of mineral content in bee bread.

Institutional Review Board Statement: All animal procedures in this study followed the guidelines provided by the National Institute of Health Guide for the Care and Use of Laboratory Animals. The ethical approval was granted by the USM Institutional Animal Care and Use Committee (USM IACUC) with the approval number: USM/IACUC/2018/(113)(933) on 28 June 2018.

Informed Consent Statement: Not applicable.

Data Availability Statement: The data are presented within the paper. Additional raw data are available on request from the corresponding author.

Acknowledgments: The authors would like to thank all Physiology staff (Normawati Ahmad, Umeer Razali, and Noraini Ishak) for their technical assistance throughout this project.

Conflicts of Interest: There are no conflicts of interest.

\section{References}

1. Bhupathiraju, S.N.; Hu, F.B. Epidemiology of obesity and diabetes and their cardiovascular complications. Circ. Res. 2016, 118, 1723-1735. [CrossRef]

2. Caleyachetty, R.; Thomas, G.N.; Toulis, K.A.; Mohammed, N.; Gokhale, K.M.; Balachandran, K.; Nirantharakumar, K. Metabolically healthy obese and incident cardiovascular disease events among 3.5 million men and women. J. Am. Coll. Cardiol. 2017, 70, 1429-1437. [CrossRef] [PubMed]

3. WHO. Cardiovascular Diseases (CVDs). World Health Organization, 2009. Available online: http://www.who.int/mediacentre/ factsheets/fs317/en/index.html (accessed on 12 January 2021).

4. Amiri, M.; Majid, H.A.; Hairi, F.; Thangiah, N.; Bulgiba, A.; Su, T.T. Prevalence and determinants of cardiovascular disease risk factors among the residents of urban community housing projects in Malaysia. BMC Public Health 2014, 14 (Suppl 3), 1-9. [CrossRef] [PubMed]

5. Casanueva, F.F.; Moreno, B.; Rodríguez-Azeredo, R.; Massien, C.; Conthe, P.; Formiguera, X.; Barrios, V.; Balkau, B. Relationship of abdominal obesity with cardiovascular disease, diabetes and hyperlipidaemia in Spain. Clin. Endocrinol. 2010, 73, 35-40. [CrossRef]

6. Jia, Z.; Nallasamy, P.; Liu, D.; Shah, H.; Li, J.Z.; Chitrakar, R.; Si, H.; McCormick, J.; Zhu, H.; Zhen, W.; et al. Luteolin protects against vascular inflammation in mice and TNF-alpha-induced monocyte adhesion to endothelial cells via suppressing IKB $\alpha /$ NF- $k B$ signaling pathway. J. Nutr. Biochem. 2015, 26, 293-302. [CrossRef]

7. Youssef, D.A.; El-Fayoumi, H.M.; Mahmoud, M.F. Beta-caryophyllene protects against diet-induced dyslipidemia and vascular inflammation in rats: Involvement of CB2 and PPAR- $\gamma$ receptors. Chem. Biol. Interact. 2019, 297, 16-24. [CrossRef] [PubMed]

8. Yin, D.; Wang, Q.; Zhou, X.; Li, Y. Endothelial dysfunction in renal arcuate arteries of obese Zucker rats: The roles of nitric oxide, endothelium-derived hyperpolarizing factors, and calcium-activated $\mathrm{K}+$ channels. PLoS ONE 2017, 12, e0183124. [CrossRef]

9. Takashima, M.; Kanamori, Y.; Kodera, Y.; Morihara, N.; Tamura, K. Aged garlic extract exerts endothelium-dependent vasorelaxant effect on rat aorta by increasing nitric oxide production. Phytomedicine 2017, 24, 56-61. [CrossRef]

10. Malyszko, J.; Bachorzewska-Gajewska, H.; Malyszko, J. Endothelial Dysfunction and nitric oxide: Albuminuria as a central marker. In Cardio-Nephrology; Springer: Cham, Switzerland, 2017; pp. 3-9.

11. Cabrera-Pastor, A.; Malaguarnera, M.; Taoro-Gonzalez, L.; Llansola, M.; Felipo, V. Extracellular cGMP modulates learning biphasically by modulating glycine receptors, CaMKII and glutamate-nitric oxide-cGMP pathway. Sci. Rep. 2016, 6, 33124. [CrossRef]

12. Kim, H.Y.; Lee, Y.J.; Han, B.H.; Yoon, J.J.; Ahn, Y.M.; Hong, M.H.; Tan, R.; Kang, D.G.; Lee, H.S. Mantidis ootheca induces vascular relaxation through PI3K/AKT-mediated nitric oxide-cyclic GMP-protein kinase G signaling in endothelial cells. J. Physiol. Pharmacol. 2017, 68, 215-221.

13. Alexandre, E.C.; Leiria, L.O.; Silva, F.H.; Mendes-Silvério, C.B.; Calmasini, F.B.; Davel, A.P.C.; Mónica, F.Z.; De Nucci, G.; Antunes, E. Soluble guanylyl cyclase (sGC) degradation and impairment of nitric oxide-mediated responses in urethra from obese mice: Reversal by the sGC activator BAY 60-2770. J. Pharmacol. Exp. Ther. 2014, 349, 2-9. [CrossRef] [PubMed]

14. Choi, D.H.; Lee, Y.J.; Kim, J.S.; Kang, D.G.; Lee, H.S. Cynanchum wilfordii ameliorates hypertension and endothelial dysfunction in rats fed with high fat/cholesterol diets. Immunopharmacol. Immunotoxicol. 2012, 34, 4-11. [CrossRef]

15. Gulhan, M.F. Therapeutic potentials of propolis and pollen on biochemical changes in reproductive function of L-NAME induced hypertensive male rats. Clin. Exp. Hypertens. 2019, 41, 292-298. [CrossRef] 
16. Liang, Y.; Kagota, S.; Maruyama, K.; Oonishi, Y.; Miyauchi-Wakuda, S.; Ito, Y.; Yamada, S.; Shinozuka, K. Royal jelly increases peripheral circulation by inducing vasorelaxation through nitric oxide production under healthy conditions. Biomed. Pharmacother. 2018, 106, 1210-1219. [CrossRef] [PubMed]

17. Zuluaga, C.M.; Serrato, J.C.; Quicazan, M.C. Chemical, nutritional and bioactive characterization of Colombian bee-bread. Chem Eng. Trans. 2015, 43, 175-180.

18. Di Cagno, R.; Filannino, P.; Cantatore, V.; Gobbettia, M. Novel solid-state fermentation of bee-collected pollen emulating the natural fermentation process of bee bread. Food Microbiol. 2019, 82, 218-230. [CrossRef] [PubMed]

19. Akhir, R.A.M.; Bakar, M.F.A.; Sanusi, S.B. Antioxidant and antimicrobial activity of stingless bee bread and propolis extracts. In Proceedings of the 2nd International Conference on Applied Science and Technology 2017 (ICAST'17), Kedah, Malaysia, 3-5 April 2017; AIP Publishing: Melville, NY, USA, 2017; p. 020090.

20. Sobral, F.; Calhelha, R.C.; Barros, L.; Duenas, M.; Tomas, A.; Santos-Buelga, C.; Vilas-Boas, M.; Ferreira, I.C.F.R. Flavonoid composition and antitumour activity of bee bread collected in northeast Portugal. Molecules 2017, 22, 248. [CrossRef] [PubMed]

21. Ceksteryte, V.; Balzekas, J. The use of beebread-Honey mixture in the treatment of liver diseases in alcohol-dependent patients. J. Chem. Technol. 2012, 2, 62-66.

22. Othman, Z.A.; Ghazali, W.S.W.; Noordin, L.; Yusof, N.A.M.; Mohamed, M. Phenolic Compounds and the Anti-Atherogenic Effect of Bee Bread in High-Fat Diet-Induced Obese Rats. Antioxidants 2019, 9, 33. [CrossRef]

23. Zhou, B.; Ren, C.; Zu, L.; Zheng, L.; Guo, L.; Gao, W. Elevated plasma migration inhibitory factor in hypertension-hyperlipidemia patients correlates with impaired endothelial function. Medicine 2016, 95, e5207. [CrossRef]

24. Bellinger, L.L.; Bernardis, L.L. Effect of dorsomedial hypothalamic nuclei knife cuts on ingestive behavior. Am. J. Physiol. Integr. Comp. Physiol. 1999, 276, R1772-R1779. [CrossRef]

25. Bhardwaj, S.; Bhattacharjee, J.; Bhatnagar, M.K.; Tyagi, S. Atherogenic index of plasma, castelli risk index and atherogenic coefficient-New parameters in assessing cardiovascular risk. Int. J. Pharm. Biol. Sci. 2013, 3, 359-364.

26. Prince, P.S.M.; Kumaran, K.S. Preventive effects of caffeic acid on lipids, lipoproteins and glycoproteins in isoproterenol induced myocardial infarcted rats. Food Res. 2012, 45, 155-160. [CrossRef]

27. Bumrungpert, A.; Pingeesakikul, T.; Tirawanchai, N.; Tuntipopipat, S.; Lilitchan, S.; Komindr, S. Effects of Ferulic Acid Supplementation on Lipid Profiles, Oxidative Stress and Inflammatory Status in Hypercholesterolemic Subjects. FASEB J. 2012, 1, 263-267.

28. Jeepipalli, S.P.K.; Du, B.; Sabitaliyevich, U.Y.; Xu, B. New insights into potential nutritional effects of dietary saponins in protecting against the development of obesity. Food Chem. 2020, 318, 126474. [CrossRef]

29. Gomaa, A.A.; El-Sers, D.A.; Al-Zokeim, N.I.; Gomaa, M.A. Amelioration of experimental metabolic syndrome induced in rats by orlistat and Corchorus olitorius leaf extract; role of adipocytokines. J. Pharm. Pharmacol. 2018, 71, 281-291. [CrossRef] [PubMed]

30. Audikovszky, M.; Pados, G.; Seres, I.; Harangi, M.; Fülöp, P.; Katona, E.; Winkler, G.; Paragh, G. Changes in lipid profile and paraoxonase activity in obese patients as a result of orlistat treatment. Orv. Hetil. 2001, 142, 2779-2783. [PubMed]

31. Tousoulis, D.; Oikonomou, E.; Economou, E.K.; Crea, F.; Kaski, J.C. Inflammatory cytokines in atherosclerosis: Current therapeutic approaches. Eur. Heart J. 2016, 37, 1723-1732. [CrossRef] [PubMed]

32. Wang, T.; He, X.; Liu, X.; Liu, Y.; Zhang, W.; Huang, Q.; Liu, W.; Xiong, L.; Tan, R.; Wang, H.; et al. Weighted gene co-expression network analysis identifies FKBP11 as a key regulator in acute aortic dissection through a NF-kB dependent pathway. Front. Physiol. 2017, 8, 1010. [CrossRef] [PubMed]

33. Suleiman, J.B.; Nna, V.U.; Zakaria, Z.; Othman, Z.A.; Bakar, A.B.A.; Mohamed, M. Obesity-induced testicular oxidative stress, inflammation and apoptosis: Protective and therapeutic effects of orlistat. Reprod. Toxicol. 2020, 95, 113-122. [CrossRef]

34. Eleazu, C.; Suleiman, J.B.; Othman, Z.A.; Nna, V.U.; Hussain, N.; Mohamed, M. Bee bread attenuates high fat diet induced renal pathology in obese rats via modulation of oxidative stress, downregulation of NF-kB mediated inflammation and Bax signalling. Arch. Physiol. Biochem. 2020, 1-17. [CrossRef] [PubMed]

35. Hamalainen, M.; Nieminen, R.; Vuorela, P.; Heinonen, M.; Moilanen, E. Anti-inflammatory effects of flavonoids: Genistein, kaempferol, quercetin, and daidzein inhibit STAT-1 and NF- $\mathrm{B}$ activations, whereas flavone, isorhamnetin, naringeni, and pelargonidin inhibit only NF-kB activation along with their inhibitory ef. Mediat. Inflamm. 2007, 2007, 045673. [CrossRef]

36. Othman, Z.A.; Zakaria, Z.; Suleiman, J.B.; Ghazali, W.S.W.; Mohamed, M. Anti-atherogenic effects of orlistat on obesity-induced vascular oxidative stress rat model. Antioxidants 2021, 10, 251. [CrossRef] [PubMed]

37. Mallat, R.K.; John, C.M.; Kendrick, D.J.; Braun, A.P. The vascular endothelium: A regulator of arterial tone and interface for the immune system. Crit. Rev. Clin. Lab. Sci. 2017, 54, 458-470. [CrossRef] [PubMed]

38. Gimbrone, M.A., Jr.; García-Cardeña, G. Endothelial cell dysfunction and the pathobiology of atherosclerosis. Circ. Res. 2016, 118, 620-636. [CrossRef] [PubMed]

39. Guo, M.; Cai, Y.; He, C.; Li, Z. Coupled Modeling of Lipid Deposition, Inflammatory Response and Intraplaque Angiogenesis in Atherosclerotic Plaque. Ann. Biomed. Eng. 2019, 47, 439-452. [CrossRef] [PubMed]

40. Basatemur, G.L.; Jørgensen, H.F.; Clarke, M.C.; Bennett, M.R.; Mallat, Z. Vascular smooth muscle cells in atherosclerosis. Nat. Rev. Cardiol. 2019, 16, 727-744. [CrossRef] [PubMed]

41. Lastra, G.; Manrique, C.; Jia, G.; Aroor, A.R.; Hayden, M.R.; Barron, B.J.; Niles, B.; Padilla, J.; Sowers, J.R. Xanthine oxidase inhibition protects against Western diet-induced aortic stiffness and impaired vasorelaxation in female mice. Am. J. Physiol. Integr. Comp. Physiol. 2017, 313, 67-77. [CrossRef] [PubMed] 
42. Safi, M.M.; Abou-Nazel, M.W.; Karawya, F.S.; Omar, A.M. The Possible Protective Effects of Inegy versus Cinnamon Oil on the Aorta of Albino Rats with Experimentally Induced Hyperlipidemia. Int. J. Clin. Exp. Med. Sci. 2016, 1, 78-91.

43. Godo, S.; Shimokawa, H. Divergent roles of endothelial nitric oxide synthases system in maintaining cardiovascular homeostasis. Free Radic. Biol. Med. 2017, 109, 4-10. [CrossRef]

44. Anwar, M.A.; Samaha, A.A.; Ballan, S.; Saleh, A.I.; Iratni, R.; Eid, A.H. Salvia fruticosa Induces vasorelaxation in rat isolated thoracic aorta: Role of the PI3K/Akt/eNOS/NO/cGMP signaling pathway. Sci. Rep. 2017, 7, 686. [CrossRef] [PubMed]

45. Chung, B.H.; Kim, S.; Kim, J.D.; Lee, J.J.; Baek, Y.Y.; Jeoung, D.; Lee, H.; Jongseon, C.; Ha, K.-S.; Won, M.-H.; et al. Syringaresinol causes vasorelaxation by elevating nitric oxide production through the phosphorylation and dimerization of endothelial nitric oxide synthase. Exp. Mol. Med. 2012, 44, 191-201. [CrossRef] [PubMed]

46. Shamsaldeen, Y.A.; Ugur, R.; Benham, C.D.; Lione, L.A. Diabetic dyslipidaemia is associated with alterations in eNOS, caveolin-1, and endothelial dysfunction in streptozotocin treated rats. Diabetes Metab. Res. Rev. 2018, 34, e2995. [CrossRef] [PubMed]

47. Schirra, C.; Xia, N.; Schuffler, A.; Heck, A.; Hasselwander, S.; Forstermann, U.; Li, H. Phosphorylation and activation of endothelial nitric oxide synthase by red fruit (Pandanus conoideus Lam) oil and its fractions. J. Ethnopharmacol. 2019, 251, 112534. [CrossRef] [PubMed]

48. Waldbauer, K.; Seiringer, G.; Sykora, C.; Dirsch, V.M.; Zehl, M.; Kopp, B. Evaluation of Apricot, Bilberry, and Elderberry Pomace Constituents and Their Potential To Enhance the Endothelial Nitric Oxide Synthase (eNOS) Activity. ACS Omega 2018, 3 , 10545-10553. [CrossRef] [PubMed]

49. Fetherolf, M.M.; Boyd, S.D.; Taylor, A.B.; Kim, H.J.; Wohlschlegel, J.A.; Blackburn, N.J.; Hart, P.J.; Winge, D.R.; Winkler, D.D. Copper-zinc superoxide dismutase is activated through a sulfenic acid intermediate at a copper ion entry site. J. Biol. Chem. 2017, 292, 12025-12040. [CrossRef]

50. Fang, X.; Wang, K.; Han, D.; He, X.; Wei, J.; Zhao, L.; Imam, M.U.; Ping, Z.; Li, Y.; Xu, Y.; et al. Dietary magnesium intake and the risk of cardiovascular disease, type 2 diabetes, and all-cause mortality: A dose-response meta-analysis of prospective cohort studies. BMC Med. 2016, 14, 210. [CrossRef]

51. Friedewald, W.; Levy, R.; Fredrickson, D. Estimation of the concentration of low-density lipoprotein cholesterol in plasma, without use of the preparative ultracentrifuge. Clin. Chem. 1972, 18, 499-502. [CrossRef] [PubMed]

52. Jeevangi, S.; Manjunath, S.; Sakhare, P. A study of anti-hyperlipidemia, hypolipedimic and anti-atherogenic activity of fruit of emblica officinalis (Amla) in high fat fed albino rats. Int. J. Med. Res. Heal. Sci. 2013, 2, 70-77.

53. Castelli, W.P.; Garrison, R.J.; Wilson, P.W.; Abbott, R.D.; Kalousdian, S.; Kannel, W.B. Incidence of coronary heart disease and lipoprotein cholesterol levels: The Framingham Study. JAMA 1986, 256, 2835-2838. [CrossRef]

54. Lee, K.; Ham, I.; Yang, G.; Lee, M.; Bu, Y.; Kim, H.; Choi, H.Y. Vasorelaxant effect of Prunus yedoensis bark. BMC Complement. Altern. Med. 2013, 13, 31. [CrossRef] [PubMed] 